\title{
EDUCAÇÃO LIBERAL E DEMOCRACIA MODERNA NO PENSAMENTO DE LEO STRAUSS
}

\author{
LIBERAL EDUCATION AND MODERN DEMOCRACY IN THE THOUGHT OF LEO STRAUSS
}

Elvis de Oliveira Mendes*

RESUMO:

Este ensaio pretende mostrar a reflexão do filósofo político contemporâneo Leo Strauss acerca da situação da educação liberal dentro da democracia liberal moderna e que, para ele, a educação liberal é a forma da qual podemos subir da democracia das massas para a democracia em seu sentido original, a saber, em sua acepção clássica ou tradicional. Em outras palavras, na ótica de Strauss a "educação liberal é o antídoto contra os efeitos corrosivos da cultura de massa" predominante no contexto das democracias modernas, neste sentido, seria a forma de oportunizar os indivíduos a entrar em diálogo com as "maiores mentes" e através desse contato privilegiado, superar a decadência intelectual e moral de nosso tempo, "a cultura de massa e sua tendência inerente de produzir nada".

PALAVRAS CHAVES: Educação liberal. Democracia. Modernidade. Leo Strauss. Cultura de massas.

\section{ABSTRACT:}

This essay aims to show the reflection of contemporary political philosopher Leo Strauss about the situation of the liberal education within the modern liberal democracy and for him, liberal education is the form that we can ascend from democracy of masses to democracy in their original sense in their classic or traditional form. In another words, in the Strauss's view the "liberal education is the counter poison against the corroding effects of the culture of masses", predominant in the context of the modern democracies, in this sense, would be the form to give a chance to individuals to have a dialogue with the "greatest minds" and through of this especial contact, to superate the intellectual and moral decay of our time, "the culture of masses and their inherent tendency to produce nothing".

KEY WORDS: Liberal education. Democracy. Modernity. Leo Strauss. Culture of masses.

\section{INTRODUÇÃO}

O pensamento filosófico político de Leo Strauss indubitavelmente se configurou como uma crítica aos diversos aspectos constitutivos daquilo que convencionalmente chamamos de modernidade. Nesse sentido, os ataques e as críticas virulentas do filósofo estão em considerável medida apontadas aos valores erigidos sob a influência do zeitgeist moderno. Nesse contexto, os esforços do filósofo político teuto americano estão direcionados a

* Mestre em Filosofia pela Universidade Federal de Pernambuco (UFPE). E-mail: elvis.oliver@live.com. 
denunciar a fragilidade de tais valores e do resultante fracasso do projeto político alicerçado nesses mesmos valores. ${ }^{1}$

Ora, mas a tarefa de Strauss não é nada fácil e nem de longe parece simples, a saber, o imaginário moderno, seus dogmas e paradigmas, exercem inequivocamente, uma influência quase que tirânica no mundo contemporâneo, em seus mais variados âmbitos, sobretudo, na educação ${ }^{2}$ em seus vários níveis. Com efeito, será este o tema central de nossa abordagem, já que para Strauss são inúmeras as dificuldades encontradas para a efetivação de uma educação liberal no contexto da democracia liberal moderna ${ }^{3}$ (STRAUSS, 1995, p. 3). O que parece de fato estar em jogo para Strauss é que toda complexidade que envolve os problemas da modernidade possuem de forma tácita ou explícita sua raiz na educação, ou melhor, na forma pela qual os indivíduos passaram a ser educados a partir da consolidação da concepção moderna de democracia.

\section{O QUE É EDUCAÇÃO LIBERAL PARA LEO STRAUSS?}

Para darmos um passo inicial, porém, de relevância fundamental às pretensões deste ensaio, necessariamente precisamos entender o que de fato Strauss pensa sobre educação liberal. Para Strauss (p. 3), “educação liberal é a educação na cultura ou em direção à cultura"4. Tal afirmação se dá ou corrobora com o fato de que o "produto final de uma educação liberal é um ser humano aculturado"5 (p. 3). Para isso, seguindo essa linha de raciocínio, os indivíduos precisam ter suas mentes cultivadas, e como um agricultor que cultiva o solo para colher frutos, o professor cultiva a mente de seus pupilos e espera em certo sentido resultados. Portanto "assim como o solo precisa de cultivadores do solo, a mente precisa de professores"6 (p. 3). Não é à toa que o termo "cultura" significa primariamente agricultura, isto é, em seu sentido originário e stricto quer dizer o cultivo de algo.

\footnotetext{
${ }^{1}$ Sobre isso consultar "The three waves of modernity" e "Political philosophy and the crisis of our times", em The city and man e What is political philosophy?. Nesses escritos Strauss tenta de forma consistente mostrar as supostas falhas do plano político moderno ocidental e seus riscos.

${ }^{2}$ Os dois textos mais importantes elaborados por Strauss e que tratam exclusivamente desse tema são: "What is liberal education?" e "Liberal education and responsibility", ambos são parte integrante da obra Liberalism ancient and modern, p. 1-8 e 9-25.

${ }^{3}$ Ler sobre isso em FULLER, 2009, pp. 241-262.

4 "Liberal education is education in culture or toward culture".

5 "The finished product of a liberal education is a cultured human being".

6 "Just as the soil needs cultivators of the soil, the mind needs teachers".
} 
Mas em meio a esses esclarecimentos, Strauss (1995, p. 3) chama atenção para um detalhe importante, o fato de que não se encontram grandes professores na mesma proporção e medida que se encontram bons agricultores. Mas quem são os grandes professores? Para Strauss, os grandes professores são as "maiores mentes" ou os "grandes espíritos" (Greatest Minds), e essas grandes mentes ou grandes espíritos não são encontrados em qualquer lugar, "talvez não haja nenhuma delas viva em seu tempo", sendo assim, nós só conseguimos dialogar com essas grandes mentes a partir do esforço de efetuar a leitura de suas obras e extrair seus grandiosos ensinamentos. Portanto, o papel da educação liberal seria o de levar os jovens a conhecer as maiores mentes e, por assim dizer, serem educados por elas, dessa maneira até os professores de nosso tempo precisam ser necessariamente bons pupilos.

Portanto, como foi dito no parágrafo anterior, as maiores mentes só podem ser acessadas através da leitura minuciosa de suas obras, isto é, tais obras devem ser estudadas “com o devido cuidado". Por outro lado, Strauss (1995, p. 3) elenca duas dificuldades ou dois problemas; primeiramente "nem todas as maiores mentes nos dizem as mesmas coisas em relação aos temas mais importantes", 7 muito pelo contrário afirma Strauss (p. 3-4): "a comunidade dessas grandiosas mentes é rachada pela discórdia e até por vários tipos de discórdia". ${ }^{8}$ Em segundo lugar, a educação liberal é a educação da cultura ocidental, mas sabemos que existem inúmeras outras culturas, porém, a educação liberal é a educação da cultura ocidental e por ser assim, isso se converte em um "paroquialismo" ou uma espécie de "catequese laica", o que de fato, contrasta inevitavelmente com o discurso da diversidade de culturas inerente ao pensamento liberal que se pretende ser uma educação eminentemente não doutrinal (indoctrination).

Ora, mas "paroquialismo" e liberalismo em sua acepção moderna são posições nitidamente contrárias e profundamente antagônicas. Constatado isso, Strauss nos conduz a um grave problema, ao fato de que inegavelmente a característica principal de nosso tempo e o discurso bravamente defendido pela educação liberal praticada nas democracias liberais modernas, como foi dito anteriormente, é o de que não existe cultura superior a outra, de que só é possível se pensar a cultura de forma plural e de que todo indivíduo ou grupo possui uma determinada cultura, portanto é um crime contra a diversidade se pensar a cultura de forma hierárquica ou valorativa. Nesse sentido, pensar o universal em detrimento do plural e relativo é também uma postura que hoje em dia é tratada com igual grau de repugnância e escárnio.

\footnotetext{
7 "The greatest minds do not all tell us the same things regarding the most important themes".

8 "The community of the greatest minds in rent by discord and even by various kinds of discord".
} 
Dessa maneira, dizer "o que é cultura" se tornou uma tarefa tanto complexa como obscura de sentido, como Strauss (1995, p. 4) explica nesta passagem:

\begin{abstract}
Nossa noção de educação liberal não parece se encaixar numa época consciente do fato de que não existe a cultura da mente humana, mas uma variedade de culturas. obviamente, "cultura", se suscetível de ser usada no plural, não é o mesmo que "culture", que é singulare tantum, só podendo ser usada no singular. A "cultura" já não é mais absoluta, ela se tornou relativa. Não é fácil dizer o que significa a cultura suscetível de ser usada no plural. Como consequência dessa obscuridade, as pessoas sugerem, explícita ou implicitamente, que a "cultura" é qualquer padrão de conduta comum a qualquer grupo humano. Assim, não hesitamos em falar de cultura de subúrbios, cultura das gangues juvenis, delinquentes ou não. Em outras palavras, todo ser humano fora do hospício é um ser humano culto, pois ele participa de uma cultura. Nas fronteiras da pesquisa surge a questão sobre se há ou não culturas entre os membros de um hospício. Se contrastarmos o uso atual de "cultura" com seu significado original, é como se alguém dissesse que o cultivo de um jardim pode consistir no jardim sendo sujo por latas vazias, garrafas de uísque e papeis amassados jogados pelo jardim de forma aleatória. ${ }^{9}$ (Tradução nossa).
\end{abstract}

Diante disto, se a educação liberal é a educação na cultura ou rumo à cultura, mas, se esse indivíduo aculturado pretendido e objetivado como produto final da educação liberal é de fato aculturado na cultura ocidental, ou a partir dos valores da cultura ocidental, então "o que pode significar educação aqui e agora?” É a questão levantada por Strauss. Nós sabemos que o princípio básico da educação liberal é a alfabetização, portanto é a educação das letras ou que parte do letramento dos indivíduos, e a democracia moderna, em considerável medida, depende da alfabetização e do letramento dos indivíduos para se manter e legitimar o poder de suas instituições representativas. Sendo assim, Strauss nos levará a outra questão que parece imprescindível; “o que é a democracia moderna?” Strauss responde que:

Antes dizia-se que a democracia é o regime que se mantém ou entra em colapso em
função da virtude: uma democracia é um regime no qual todos, ou a maioria dos
adultos, são homens de virtude. Como a virtude parece exigir conhecimento, é um
regime no qual todos, ou a maioria dos adultos, são virtuosos e sábios, ou a
sociedade na qual todos, ou a maioria dos adultos, desenvolveram sua razão a um
nível alto - ou a sociedade racional. A democracia deveria ser uma aristocracia que

\footnotetext{
9 "Our notion of liberal education does not seem to fit an age which is aware of the fact that there is not the culture of the human mind, but a variety of cultures. Obviously, culture if susceptible of being used in the plural is not quite the same thing as culture which is a singular tantum, which can be used only in the singular. Culture is now no longer as people say, an absolute, but has become relative. It is not easy to say to say what culture susceptible of being used in the plural means. As a consequence of this obscurity people have suggested, explicitly or implicitly, thatm culture is any pattern of conduct common to any human group. Hence we do not hesitate to speak of the cultures of suburbia or of the cultures of juvenile gangs, both nondelinquent and delinquent. In order words, every human being outside of lunatic asylum is a cultured human being, for he participates in a culture. At the frontiers of research there arises the question as to whether there are not cultures also inmates of lunatic asylums. If we contrast the present-day usage of 'culture' with the original meaning, it is as if someone would say that the cultivation of a garden may consist of the garden's being littered with empty tin cans and whisky bottles and used papers of various descriptions thrown around the garden at random."
} 
se ampliou para uma aristocracia universal. Antes do surgimento da democracia moderna, havia dúvidas sobre se a democracia entendida dessa forma era possível. ${ }^{10}$ (STRAUSS, 1995, p. 4, tradução nossa).

Strauss parece aqui colocar frente a frente duas concepções de democracia: por um lado a democracia em seu sentido originário ou ideal, por outro, a democracia moderna ou como de fato ela é. Pois bem, a democracia moderna se fundou na perspectiva de ser uma aristocracia universal, uma única nação, próspera e pacífica, livre das desigualdades, da escravidão e dos preconceitos, uma espécie de paraíso na terra, construído pelos homens e fundado pelos avanços da racionalidade e do intelecto humano. ${ }^{11}$ Mas basta fazer um passeio matinal numa grande cidade, comprar o jornal ou simplesmente ligar a TV no canal de notícias, e logo perceberemos que a democracia moderna se tornou algo distante disso. A pretensão de que as massas dominassem se configurou na verdade como um novo tipo de escravidão das massas sob a égide de uma nova ideologia de liberdade envolvida pela bandeira revolucionária que construiu a "ferro e fogo" o empreendimento das sociedades contemporâneas baseado nos "ideais modernos" de "liberté, fraternité et igualité". Sendo assim, o sonho revolucionário na prática se converteu em uma sociedade castradora, universalista e aprisionada pelo consumo, em que grande maioria da massa sequer compreende suas próprias atividades e comportamentos. Nesse sentido, o que se consolidou de fato foi um tipo de sociedade na qual "um grande grupo de pessoas, provavelmente a grande maioria da geração mais jovem, toma como verdadeiras as visões fomentadas pelo governo. Isso, se não ocorre de imediato, ocorre ao menos com o passar do tempo"12 (STRAUSS, 1988, p. 25).

Dessa forma, "o que é denominado liberdade de pensamento se resume a - ou, para todos os fins práticos, consiste em - poder escolher entre duas ou mais visões apresentadas pela pequena minoria de pessoas que atuam como oradores ou escritores públicos" (STRAUSS, 1998, p. 23) $)^{13}$. Assim, as massas que, segundo os pressupostos da democracia liberal moderna, iriam dominar, na verdade se tornaram incapazes de pensar suas próprias

\footnotetext{
10 "It was once said that democracy is the regime that stands or falls by virtue: a democracy is a regime in which all or most adults are men of virtue, and since virtue seems to require wisdom, a regime in which all or most adults are virtues or wise, or the society in which has broadened into the universal aristocracy. Prior to the emergence of modern democracy some doubts were felt whether democracy thus understood is possible."

${ }^{11}$ Conferir o que Strauss fala sobre isso em STRAUSS, 1964/1992, p. 1-12.

12 "A large section of the people, probably the great majority of the younger generation, accepts the governmentsponsored views as true, if not at once at least after a time".

13 "What is called freedom of thought in a large number of cases amounts to - and even for all practical purposes consists of - the ability to choose between two or more different views presented by the small minority of people who are public speakers or writers".
} 
práticas em prol de algo verdadeiramente outro, e são apenas levadas a desenvolver "uma das virtudes mais importantes exigidas para o funcionamento sem trancos da democracia, no que se refere às massas, que é a apatia eleitoral, ou a falta de espírito público" (STRAUSS, 1995, p. 5). Ainda neste mesmo contexto, o total desinteresse de maioria dos indivíduos pelos assuntos realmente importantes para a sociedade corrobora, portanto, realmente, não para o domínio das massas, mas para o domínio da cultura de massas (p. 5). Por outro lado, a cultura de massas exige certo esforço, por ser rápida, perecível e obedecer à freneticidade do mercado e da indústria. Isso chega a um momento ou ponto limítrofe que contrasta radicalmente com a democracia, que por sua vez, mesmo sendo considerada a "concha que protege a cultura de massa", exige, em longo prazo, qualidades de um tipo totalmente diferente: qualidades de dedicação, concentração, amplitude e profundidade (p. 5).

Com efeito, é diante da necessidade de respirar nessas águas turvas e paralisantes da cultura de massa que a democracia se defronta diretamente com sua maior dificuldade, a saber, garantir as liberdades individuais intrínsecas em seu discurso e ao mesmo tempo fazer seus órgãos representativos funcionarem e assim garantir a manutenção de seu establishment social. Portanto, constatado isso, para Strauss é possível entender para que serve de fato a educação liberal no contexto da democracia moderna; para ele a educação seria então a única forma de superar o vazio intelectual e moral disseminado pela cultura de massa e de oportunizar que alguns indivíduos que apresentem as aptidões necessárias a uma emancipação consigam enxergar para além dos limites da "caverna". Como podemos observar nas palavras do próprio Strauss (1995, p. 5):

\begin{abstract}
A educação liberal é o antídoto para a cultura de massa, para os efeitos corrosivos da cultura de massa, para sua tendência inerente de produzir nada, a não ser "especialistas sem espírito ou visão e apreciadores do prazer sem coração". A educação liberal é a escada pela qual tentamos subir da democracia das massas à democracia em seu sentido original. A educação liberal é o esforço necessário para fundar uma aristocracia dentro da sociedade de democracia de massa. A educação liberal lembra aos membros de uma democracia de massa que tenham ouvidos para ouvir sobre a grandiosidade humana. ${ }^{14}$ (tradução nossa).
\end{abstract}

Porém, há também aqueles que propõem um retorno ao primitivo, ao homem em seu estado natural, e simplesmente exercem o seguinte questionamento; "não podemos virar as

\footnotetext{
14 "Liberal education is the counterpoison to mass culture to the corroding effects of mass culture, to its inherent tendency to produce nothing but 'specialists without spirit or vision and voluptuaries without heart.' Liberal education is the ladder by which we try to ascend from mass democracy to democracy as originally meant. Liberal education in the necessary endeavor to found an aristocracy within democratic mass society. Liberal education reminds those members of a mass democracy who have ears, to hear, pf human greatness".
} 
costas para a sociedade moderna? Não podemos voltar à natureza, à vida em tribos não alfabetizadas?” (STRAUSS, 1995, p. 5-6). Como propusera Rousseau ${ }^{15}$, uma solução no retorno a vida em tribos, na floresta, na agricultura de subsistência longe da complexidade e do caos das grandes metrópoles e da devastadora vida industrial. Para Strauss (1953/1971, p. 252-294), essa perspectiva romântica da vida não é possível, e se fosse não seria bom, não daria os resultados esperados. De fato, homens não alfabetizados não são capazes de construir valores e bens em comum, a sociedade só foi possível a partir do reconhecimento do que é bom, e isso só foi possível através das letras. São as letras que possibilitam a constituição de regras e valores essenciais à vida, e que essas regras e valores essenciais à vida fossem passados de geração para geração, daí o caráter ancestral e, por assim dizer, divino da moralidade ou dos códigos morais que tornou possível a humanidade já que até então não conhecemos nenhum grupo humano que não tenha vivido sob uma tábua de valores.

Dito isto, Strauss (1995, p. 6) nos conduzirá a um novo questionamento; "De que forma a educação liberal nos lembra da grandiosidade humana?” Ora, a educação liberal é a forma pela qual os homens passam seus conhecimentos e sua excelência de geração para geração, apenas uma sociedade alfabetizada e devidamente letrada é capaz de tal feito. Portanto, a educação liberal seria o caminho no qual o homem alcança a virtude e a felicidade, como sugere Platão. Porém como o conhecimento do todo ou da totalidade das coisas é impossível, estaria aí a motivação principal da insatisfação humana. Portanto, só o filósofo seria capaz de adquirir tal virtude e tão alto nível de conhecimento, por ser ele aquele que em sua prática genuína e autêntica busca ininterruptamente conhecer, e leva essa busca do conhecer até suas últimas consequências.

Entretanto, "a partir disso, concluímos que não podemos ser filósofos - não podemos adquirir a forma mais alta de educação". E diante desta última afirmação, seria pertinente a pergunta: e os professores de filosofia? Ironicamente, Strauss (p. 7) responde: "Não devemos nos deixar enganar pelo fato de que encontramos muitas pessoas que se dizem filósofos. Elas empregam uma expressão vaga, talvez por conveniência administrativa. Muitas vezes, querem dizer meramente que são membros de departamentos de filosofia"16. Strauss endossa ainda essa afirmação ao enfatizar que "é tão absurdo esperar que membros de departamentos de

\footnotetext{
${ }^{15}$ Para Strauss (1953/1971, p. 252-253), Rousseau foi quem primeiro colocou a modernidade em crise ao suspeitar das pretensões de seus contemporâneos do movimento Iluminista.

16 "We must not be deceived by the fact that we meet many people who say that they are philosophers. For those people employ a loose expression which is perhaps necessitated by administrative convenience. Often they mean merely that they are members of philosophy departments".
} 
filosofia sejam filósofos quanto é absurdo esperar que membros de departamentos de arte

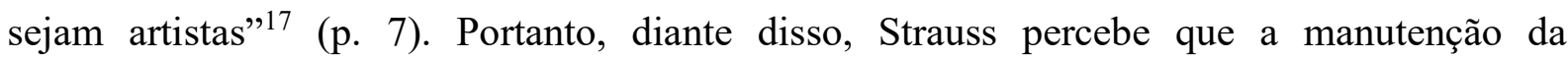
democracia moderna depende da estupidez de maior parte da massa como garantia assim como já foi dito anteriormente; "da apatia eleitoral e da falta de espírito público", comportamento fundamental para administração da ordem e seu conservantismo, já que a ordem e a conservação se tornam na prática mais importantes que a virtude e a excelência. Sobre isso, explica Claude Lefort (1999, p. 273):

\begin{abstract}
Vale a pena observar que Strauss substitui o problema do capitalismo pelo problema da cultura de massas - julgando altamente significativa a paixão pelo esporte que guia o leitor do jornal - e da democracia: o ultimo homem é para ele, como para Nietzsche, o homem democrático, o homem do rebanho. E igualmente vale observar que ele não visa nem o surgimento de novos profetas, nem o poderoso renascimento de ideais antigos; basta-lhe unicamente a defesa da educação liberal como "contraveneno para a cultura de massas".
\end{abstract}

Dado então esse caráter "missionário" e, em certo sentido, com um tom humanístico, porém menos idealista e consciente das dificuldades, Strauss afirma que "a educação liberal consiste em escutar a conversa entre as maiores mentes. Mas aqui somos confrontados com uma grande dificuldade, a de que essa conversa não ocorre sem nossa ajuda - o fato de que devemos fazer essa conversa acontecer" ${ }^{\prime 18}$ (STRAUSS, 1995, p. 8). E o professor que também é pupilo, deve mediar o diálogo com as maiores mentes ou os grandiosos espíritos. Dessa forma, viabilizar esta troca, transformar monólogos, em diálogos, e transformar diálogos ensinamentos sobre os temas fundamentais da vida do homem como homem.

Em última análise, Strauss insiste que a educação liberal é o esforço necessário para fundar uma aristocracia dentro da sociedade de democracia de massas. A educação liberal lembra aos membros de uma democracia de massas que tenham ouvidos para ouvir sobre a grandiosidade humana. Já que a educação liberal ou o diálogo com as maiores mentes pode libertar os indivíduos da vulgaridade, ou do que Strauss, sob a influência dos antigos, prefere usar o termo grego para vulgaridade que é “apeirokália”, cuja tradução é "falta de experiência em coisas bonitas" (STRAUSS, 1995, p. 8), por assim dizer, a educação liberal nos permitiria uma experiência das coisas bonitas.

\footnotetext{
17 "It is as absurd to expect members of philosophy departments to be philosophers as it is to expect members of art departments to be artists".

18 "Liberal education consists in listening the conversation among the greatest minds. But here we are confronted with the overwhelming difficulty that this conversation does not take place without our help-that in fact we must bring about that conversation".
} 


\section{CONSIDERAÇÕES FINAIS}

Diante do que Strauss aponta como o declínio intelectual e moral vivido de forma aguda nas sociedades de massas, não é difícil perceber em seus textos que ele desaprova radicalmente os fundamentos e os valores que alicerçam a democracia liberal moderna, e advoga em favor da antiguidade grega e vê no tipo de democracia que lá surgira o seu tipo original, e por assim dizer, um tipo melhor de experiência política. Portanto, nesse contexto, Strauss vê no âmago mesmo da pólis um referencial para se propor um repensamento acerca dos caminhos políticos da democracia liberal nas sociedades contemporâneas.

Como podemos perceber no desenvolvimento deste breve ensaio, Strauss, diante da constatação da impossibilidade de um retorno prático aos antigos, vê na educação liberal uma forma de superar o vácuo produzido pela cultura de massas; uma forma que os indivíduos possam ouvir a excelência das "maiores mentes" ou dos "grandiosos espíritos" e participar desse diálogo privilegiado. Com efeito, essa seria a forma, segundo Strauss, de se criar uma aristocracia dentro da democracia de massas. Assim, ao darmos a oportunidade a todos, daríamos oportunidade também àqueles que se preocupam e buscam por virtudes e excelência.

\section{REFERÊNCIAS}

FULLER, T. The complementarity of political philosophy and liberal education in the thought of Leo Strauss. In: SMITH, S. B. The Cambridge Companion to Leo Strauss. Cambridge: Cambridge University Press, 2009, p. 241-262.

LEFORT, C. Três Notas Sobre Leo Strauss. In: Desafios da escrita política. São Paulo: Discurso Editorial, 1999.

STRAUSS, L. Liberalism Ancient and Modern - Leo Strauss. Foreword by Allan Bloom. University of Chicago Press Edition 1995.

STRAUSS, L. Natural right and history. Chicago: The University of Chicago Press, 1971 (1953). Tradução portuguesa de Miguel Morgado: Direito natural e história. Lisboa: Edições 70, 2009. Tradução para o português Brasileiro de Bruno Costa Simões: Direito natural e história. São Paulo: Editora WMF Martins Fontes, 2014.

STRAUSS, L. Persecution and the art of writing. Chicago: The University of Chicago Press, 1988 (1952). 
STRAUSS, L. The City and Man. Chicago: The University of Chicago Press, 1992 (1964).

STRAUSS, L. What is political philosophy? And other studies. Chicago: The University of Chicago Press, 1988 (1959). 